\title{
Pathophysiology of Portal Hypertension
}

\author{
Yasuko Iwakiri, Ph.D. \\ Section of Digestive Diseases, Department of Internal Medicine, Yale University School of \\ Medicine, New Haven, CT
}

\begin{abstract}
Portal hypertension is a major complication of liver disease, which results from a variety of pathological conditions that increase the resistance to the portal blood flow into the liver. The primary cause of portal hypertension in cirrhosis is an increase in intrahepatic vascular resistance due to massive structural changes associated with fibrosis and increased vascular tone in the hepatic microcirculation. As portal hypertension develops, the formation of collateral vessels and arterial vasodilation progress, which results in increased blood flow to the portal circulation. Eventually the hyperdynamic circulatory syndrome develops, leading to esophageal varices or ascites. This review article will summarize the factors that increase 1) intrahepatic vascular resistance and 2) the blood flow in the splanchnic and systemic circulations in liver cirrhosis. Finally, the future directions of basic/clinical research in portal hypertension will be discussed.
\end{abstract}

\section{Keywords}

Hyperdynamic circulation; fibrosis; cirrhosis; nitric oxide; lymphatic system; splenomegaly

\section{Introduction}

Portal hypertension is a detrimental complication resulting from obstruction of portal blood flow, such as cirrhosis or portal vein thrombosis. ${ }^{1,2}$ In liver cirrhosis, increased intrahepatic vascular resistance to the portal flow elevates portal pressure and leads to portal hypertension (Figure 1). Once portal hypertension develops, it influences extrahepatic vascular beds in the splanchnic and systemic circulations, causing collateral vessel formation and arterial vasodilation. This helps to increase the blood flow into the portal vein, which exacerbates portal hypertension and eventually brings the hyperdynamic circulatory syndrome. ${ }^{1,2}$ Consequently, esophageal varices or ascites develops. This review article will discuss recent advances in understanding of factors that contribute to: 1) an increase in intrahepatic vascular resistance and 2) an increase in blood flow in the splanchnic and systemic circulations, and 3) the future directions of basic/clinical research in portal hypertension.

(C) 2013 Elsevier Inc. All rights reserved.

1080 LMP, 333 Cedar Street, Section of Digestive Diseases, Yale University School of Medicine, New Haven, CT 06520 U.S.A. Phone \#: 203-785-6204 Fax \#: 203-785-7273 yasuko.iwakiri@yale.edu.

Publisher's Disclaimer: This is a PDF file of an unedited manuscript that has been accepted for publication. As a service to our customers we are providing this early version of the manuscript. The manuscript will undergo copyediting, typesetting, and review of the resulting proof before it is published in its final citable form. Please note that during the production process errors may be discovered which could affect the content, and all legal disclaimers that apply to the journal pertain.

Disclosure The author has nothing to disclose. 


\section{Intrahepatic circulation}

An overview-The primary cause of portal hypertension in cirrhosis is an increase in intrahepatic vascular resistance. In cirrhosis, increased intrahepatic vascular resistance is a result of massive structural changes associated with fibrosis/cirrhosis and intrahepatic vasoconstriction $^{2-4}$. It is reported that intrahepatic vasoconstriction accounts for at least $25 \%$ of increased intrahepatic vascular resistance. ${ }^{5}$ Phenotypic changes in hepatic cells, such as hepatic stellate cells (HSCs) and liver sinusoidal endothelial cells (LSECs), are known to play pivotal roles in increased intrahepatic vascular resistance and have been studied intensively. This section summarizes important factors that increase intrahepatic vascular resistance in liver fibrosis/cirrhosis.

1. Endothelial cell dysfunction-LSECs are the first line of defense protecting the liver from injury ${ }^{2}$, and the cells exert diverse effects on liver functions including blood clearance, vascular tone, immunity, hepatocyte growth ${ }^{6}$, and angiogenesis/sinusoidal remodeling. ${ }^{7,8}$ Therefore, LSEC dysfunction could lead to impaired vasomotor control (primarily vasoconstrictive), inflammation, fibrosis, and impaired liver regeneration ${ }^{1,9}$, all of which facilitate the development of liver cirrhosis and portal hypertension.

Decreased vasodilators: Nitric oxide (NO) is likely the most potent vasodilator molecule known today. In cirrhotic livers, NO production/bioavailability is significantly diminished, which contributes to increased intrahepatic vascular resistance. ${ }^{2,9-12}$ At least two mechanisms explain the decreased NO production. First, the NO synthesizing enzyme endothelial NO synthase (eNOS) is inhibited by negative regulators (such as caveolin-1), which are up-regulated during cirrhosis; as a result, NO production decreases. ${ }^{11}$ Details regarding eNOS regulation in liver cirrhosis can be found elsewhere. ${ }^{2,12}$ Second, oxidative stress is increased in cirrhosis. LSECs receive oxidative stress in response to a wide variety of agents, such as bacterial endotoxins, viruses, drugs, and ethanol. ${ }^{13-15}$ During cirrhosis, increased superoxide radicals spontaneously react with NO to form peroxynitrite (ONOO-), an endogenous toxicant ${ }^{16}$, thereby decreasing NOs bioavailability as a vasodilator. ${ }^{13}$ Antioxidant molecules such as vitamin $\mathrm{C}^{14}$, vitamin $\mathrm{E}^{17}$, superoxide dismutase (SOD) ${ }^{15}, 18$, and $\mathrm{N}$-acetylcysteine ${ }^{19}$, have been shown to ameliorate intrahepatic vascular resistance and portal hypertension.

Increased vasoconstrictors: In cirrhosis, not only are vasodilators decreased, but vasoconstrictors, such as thromboxane $\mathrm{A} 2\left(\mathrm{TXA}_{2}\right)$, are also increased. $\mathrm{TXA}_{2}$ is produced by the action of COX-1 in LSECs. ${ }^{20}$ The activity of COX-1 increases in cirrhotic livers, which results in greater quantities of $\mathrm{TXA}_{2}$ and thereby increased intrahepatic vascular resistance. Inhibition of $\mathrm{TXA}_{2}$ by the prostaglandin $\mathrm{H}_{2} / \mathrm{TXA}_{2}$ receptor blocker, SQ-29548, or blocking COX-1 activity by the COX-1 inhibitor, SC-560, attenuates the increased intrahepatic vascular resistance. ${ }^{20,21}$ ET-1 is another important vasoconstrictor when it binds to receptors on $\mathrm{HSCs}^{22-24}$

2. Activated hepatic stellate cells-HSCs are perisinusoidal and pericyte-like cells, and reside in the space between LSECs and hepatocytes. In response to liver injury, HSCs are activated and transformed into myofibroblasts, which start to express several proinflammatory and fibrotic genes. Importantly, HSCs become contractile in an activated state. ${ }^{22,25-27}$ Increased recruitment of these activated HSCs around newly formed sinusoidal vessels increases intrahepatic vascular resistance in cirrhosis (Figure 2). ${ }^{8,28,29}$ Therefore, activated HSCs play a crucial role in the development of portal hypertension due to their contractile phenotype. 
Furthermore, activated HSCs display a decreased response to vasodilators, such as NO. ${ }^{30}$ In addition, ET-1, which is increased in cirrhosis, enhances the contractions of HSCs. ${ }^{25-27}$ Increased ET-1 production and decreased NO production in cirrhotic livers, therefore, augment intrahepatic resistance to the portal blood flow through activated HSCs, which facilitates the development of portal hypertension. However, the manipulation of ET receptors with ET receptor antagonists is complex due to their differential vasoactive effects based on their cellular locations.

3. Angiogenesis in the liver-In portal hypertension, angiogenesis plays a crucial role in intrahepatic circulation. An increased number of vessels in the fibrotic septa and the surrounding regenerative nodules has been observed in cirrhotic livers. ${ }^{31}$ Activated HSCs and/or other myofibroblasts such as portal myofibroblasts are thought to promote angiogenesis in liver cirrhosis. In fact, activated HSCs activate LSECs by releasing angiogenic factors, such as angiopoietin $8,32,33$ and vascular endothelial growth factor $(\mathrm{VEGF}){ }^{34}$

Irregular flow patterns, which are generated as a result of splitting (or intussusceptive) angiogenesis, may contribute to an increase in intrahepatic vascular resistance. In splitting angiogenesis, the two opposing walls of a capillary stretch and connect to each other, forming an intraluminal pillar. The junctions of the opposing endothelial cells are restructured, and the growth of the pillar is promoted. Finally, the capillary splits into two new vessels. ${ }^{35}$ It has been reported that conditional Notch 1 knockout mice develop splitting angiogenesis, nodular regenerative hyperplasia, and portal hypertension. LSECs from these knockout mice exhibit reduced endothelial fenestrae. These observations indicate that Notch 1 is necessary for LSEC fenestration, and that the absence of Notch 1 leads to pathological angiogenesis, the development of nodular regenerative hyperplasia, and portal hypertension. 36

\section{Extrahepatic circulation}

\section{An overview}

Once portal hypertension develops, porto-systemic collateral vessels form. Blood from the digestive organs diverts into these collateral vessels, but portal blood flowing from the splanchnic circulation increases to compensate for the blood escaping into the collateral vessels. Increased portal blood flow exacerbates portal hypertension. Furthermore, arterial vasodilation in the splanchnic and systemic circulations observed in cirrhosis helps to increase the blood flow to the portal vein. Therefore, reducing the collateral vessel formation alone would not ameliorate portal hypertension. Inhibiting arterial vasodilation in the splanchnic circulation to reduce blood flow to portal vein together is important in the treatment of portal hypertension. ${ }^{2}$ This section discusses the mechanisms of collateral vessel formation and arterial vasodilation in the splanchnic and systemic circulations in cirrhosis with portal hypertension.

\section{Collateral vessel formation}

Porto-systemic collateral vessels develop in response to an increase in portal pressure. These collateral vessels form through the opening of pre-existing vessels or angiogenesis 37,38 , and are known to cause serious complications, including variceal bleeding and hepatic encephalopathy. ${ }^{2,39,40}$ A change in portal pressure is thought to be detected first by the intestinal microcircular vascular bed, followed by arteries of the splanchnic circulation. ${ }^{41}$ Subsequently, these vascular beds generate various angiogenic factors, such as VEGF ${ }^{42-44}$ and placental growth factor $(\mathrm{PlGF})^{45}$, which promote the formation of porto-systemic collaterals. 
Studies in experimental models of portal hypertension and cirrhosis have shown that portosystemic collaterals are reduced by 18 to $78 \%$ with treatment by anti-VEGFR $2^{46}$, a combination of anti-VEGF (rapamycin)/anti-PDGF (Gleevec) ${ }^{47}$, anti-PIGF ${ }^{45}$, apelin antagonist ${ }^{48}$, sorafenib ${ }^{49}, 50$, and a cannabinoid receptor 2 agonist. ${ }^{51}$ However, the reduction of these collaterals does not necessarily decrease portal pressure because it does not substantially change the blood flow to the portal vein. Therefore, the concomitant mitigation of arterial vasodilation is also needed to reduce portal pressure.

\section{Arterial vasodilation in the splanchnic and systemic circulations}

Vasodilation-NO is the most important vasodilator molecule that contributes to excessive vasodilation observed in the arterial splanchnic and systemic circulations in portal hypertension. Experimental models of portal hypertension with or without cirrhosis have shown that other vasodilator molecules, such as carbon monoxide (CO), prostacyclin (PGIs), endocannabinoids, and endothelium-derived hyperpolarizing factor (EDHF) are also induced. 2, 9, 12 The identity of EDHF is currently unknown, and the candidates include arachidonic acid metabolites [epoxyeicosatrienoic acid (EET)], potassium ions $\left(\mathrm{K}^{+}\right)$, components of gap junctions, or hydrogen peroxide. ${ }^{2}$

An increase in portal pressure triggers eNOS activation and subsequent NO overproduction. Changes in portal pressure are detected at different vascular beds depending on the severity of portal hypertension. ${ }^{41} \mathrm{~A}$ small increase in portal pressure is sensed first by the intestinal microcirculation and increases VEGF production with a subsequent increase in eNOS levels in the intestinal microcirculation. When portal pressure further increases and reaches a certain level, vasodilation develops in the arterial splanchnic circulation (i.e., the mesenteric arteries). It is postulated that mechanical forces including cyclic strains and shear stress, which are caused by an increased blood flow associated with an increased portal pressure, activate eNOS and lead to NO production. ${ }^{41,46,52-54}$ Subsequently, vasodilation develops in the arterial systemic circulation (i.e., the aorta).

Hypocontractility-Hypocontractility, decreased contractility to vasoconstrictors, is a characteristic of the arterial splanchnic and systemic circulations in portal hypertension. This phenomenon occurs largely due to the presence of excessive vasodilator molecules (i.e., NO) and the resulting excessive arterial vasodilation, but is to some degree attributable to various molecules produced in smooth muscle cells and neurons. Those molecules include endocannabinoids (vasodilators) ${ }^{55,56}$, neuropeptide $\mathrm{Y}^{57}$, urotensin $\mathrm{II}^{58,59}$, angiotensin ${ }^{60}$, and bradykinin ${ }^{61,62}$ (all vasoconstrictors), with the vasodilators increased and the vasoconstrictors decreased.

Neural factors-Neural factors are postulated to be involved in the development of the hyperdynamic circulatory syndrome, especially through the sympathetic system. ${ }^{57,63,64}$ It is reported that sympathetic nerve atrophy/regression observed in the mesenteric arteries of portal hypertensive rats contributes to vasodilation and/or hypocontractility of those arteries. ${ }^{65,} 66$ The role of neural factors in decreased contractile responses has not yet been fully understood and is an important area to be explored.

Structural changes of arteries-The thinning of arterial walls is observed in the splanchnic and systemic circulations of rats with cirrhotic livers. ${ }^{67,68}$ While this arterial thinning results from hemodynamic changes caused by portal hypertension, it may also sustain arterial vasodilation and worsen portal hypertension. ${ }^{2,}{ }^{24}$ While NO plays a role at least in part, the molecular mechanisms responsible for arterial thinning remain to be fully elucidated. 


\section{Future directions}

\section{An overview}

Four important areas in the study of portal hypertension that have not been sufficiently explored are specified.

\section{Microflora/bacterial translocation}

In recent years, an accumulating body of evidence suggests the importance of gut microflora and bacterial translocation for the pathogenesis of a variety of diseases. Due to the anatomically-close location and the connection through the vascular system, the liver is continuously exposed to microbial products from the gut. ${ }^{69}$ It has been known that bacterial translation is closely related to the development of ascites. ${ }^{70}$ In addition, small changes in portal pressure are first sensed in the intestinal microcirculation. Increased portal pressure caused by portal hypertension may influence the gut-liver axis, further advance the pathology of liver fibrosis/cirrhosis, and exacerbate portal hypertension itself. Therefore, gut microflora may have an important role in a pathological loop that develops and maintains portal hypertension. Additionally, microflora may influence cytokine/chemokine production in the liver, which may also exacerbate portal hypertension.

\section{Stem cell therapy}

Stem cell therapy has received considerable attention as an alternative to liver transplantation. Indeed, studies have shown that stem cell transplantation improved liver functions in cirrhotic patients ${ }^{71,72}$ as well as experimental models of liver cirrhosis. ${ }^{73,74}$ While stem cell therapy has shown promising effects on the amelioration of liver fibrosis and portal hypertension, more studies are still needed.

\section{The lymphatic system}

The lymphatic system plays a central role in ascites and edema formation. ${ }^{75}$ Further, an association between lymphangiogenesis and portal hypertension has been reported. ${ }^{76}$ However, the detailed role and mechanisms of the lymphatic system in liver cirrhosis and portal hypertension are largely unknown, and these are important areas to be explored. ${ }^{77,78}$

\section{Splenomegaly}

Spleen stiffness has recently received considerable attention as an indicator of portal hypertension ${ }^{79}$ because it can be examined by non-invasive imaging systems such as transient elastrography ${ }^{80}$ and acoustic radiation force impulse imaging. ${ }^{79,}{ }^{81}$ Some studies also suggest that spleen stiffness could predict the presence of varices ${ }^{79-81}$ or ascites. ${ }^{82} \mathrm{An}$ experimental model of cirrhosis with portal hypertension has demonstrated that portal pressure positively correlated with the spleen size. ${ }^{42}$

In addition, a study using rats with partial portal vein ligation (PVL) showed that fibrosis and angiogenesis in the spleen was accompanied with splenomegaly induced by PVL, and that administration of rapamycin, an immunosuppressive agent, reduced splenomegaly as well as fibrosis and angiogenesis in the spleen. ${ }^{83}$ Currently, the detailed mechanisms of how portal pressure induces splenomegaly remain to be fully elucidated.

\section{Summary/Conclusion}

With our knowledge of vascular biology, our understanding of the pathogenesis of portal hypertension has significantly advanced, revealing how vascular abnormalities both inside and outside the liver contribute to portal hypertension. ${ }^{84}$ To ameliorate portal hypertension, 
first and foremost, a decrease in intrahepatic vascular resistance in cirrhotic liver is needed. Therefore, an increased production of vasodilator molecules in LSECs and a decrease in HSC contraction are important. For example, induction of apoptosis of enhanced activated $\mathrm{HSCs}^{85,86}$, thereby decreasing contractile HSCs, could be a useful therapeutic strategy to decrease portal pressure.

\section{Acknowledgments}

This work was supported by grant R01DK082600 from the National Institutes of Health.

\section{References}

1. Bosch J. Vascular deterioration in cirrhosis: the big picture. J Clin Gastroenterol. 2007; 41(Suppl 3):S247-53. [PubMed: 17975472]

2. Iwakiri Y, Groszmann RJ. The hyperdynamic circulation of chronic liver diseases: from the patient to the molecule. Hepatology. 2006; 43:S121-31. [PubMed: 16447289]

3. Rockey, DC. Cell and molecular mechanisms of increased intrahepatic resistance and hemodynamic correlates. Humana Press Inc; Totowa, NJ: 2005.

4. Pinzani, M.; Vizzutti, F. Anatomy and vascular biology of the cells in the portal circulation. Humana Press Inc; Totowa, NJ: 2005.

5. Wiest R, Groszmann RJ. The paradox of nitric oxide in cirrhosis and portal hypertension: too much, not enough. Hepatology. 2002; 35:478-91. [PubMed: 11826425]

6. Ding BS, Nolan DJ, Butler JM, et al. Inductive angiocrine signals from sinusoidal endothelium are required for liver regeneration. Nature. 2010; 468:310-5. [PubMed: 21068842]

7. Jagavelu K, Routray C, Shergill U, et al. Endothelial cell toll-like receptor 4 regulates fibrosisassociated angiogenesis in the liver. Hepatology. 2010; 52:590-601. [PubMed: 20564354]

8. Thabut D, Shah V. Intrahepatic angiogenesis and sinusoidal remodeling in chronic liver disease: new targets for the treatment of portal hypertension? J Hepatol. 2010; 53:976-80. [PubMed: 20800926]

9. Iwakiri Y, Groszmann RJ. Vascular endothelial dysfunction in cirrhosis. J Hepatol. 2007; 46:92734. [PubMed: 17391799]

10. Shah V, Haddad FG, Garcia-Cardena G, et al. Liver sinusoidal endothelial cells are responsible for nitric oxide modulation of resistance in the hepatic sinusoids. Journal of Clinical Investigation. 1997; 100:2923-30. [PubMed: 9389760]

11. Shah V, Toruner M, Haddad F, et al. Impaired endothelial nitric oxide synthase activity associated with enhanced caveolin binding in experimental cirrhosis in the rat. Gastroenterology. 1999; 117:1222-8. [PubMed: 10535886]

12. Iwakiri Y. The molecules: mechanisms of arterial vasodilatation observed in the splanchnic and systemic circulation in portal hypertension. J Clin Gastroenterol. 2007; 41:S288-94. [PubMed: 17975478]

13. Gracia-Sancho J, Lavina B, Rodriguez-Vilarrupla A, et al. Increased oxidative stress in cirrhotic rat livers: A potential mechanism contributing to reduced nitric oxide bioavailability. Hepatology. 2008; 47:1248-56. [PubMed: 18273863]

14. Hernandez-Guerra M, Garcia-Pagan JC, Turnes J, et al. Ascorbic acid improves the intrahepatic endothelial dysfunction of patients with cirrhosis and portal hypertension. Hepatology. 2006; 43:485-91. [PubMed: 16496307]

15. Lavina B, Gracia-Sancho J, Rodriguez-Vilarrupla A, et al. Superoxide dismutase gene transfer reduces portal pressure in CCl4 cirrhotic rats with portal hypertension. Gut. 2009; 58:118-25. [PubMed: 18829979]

16. Radi R. Peroxynitrite, a stealthy biological oxidant. J Biol Chem. 2013; 288:26464-72. [PubMed: 23861390]

17. Yang YY, Lee TY, Huang YT, et al. Asymmetric dimethylarginine (ADMA) determines the improvement of hepatic endothelial dysfunction by vitamin $\mathrm{E}$ in cirrhotic rats. Liver Int. 2012; 32:48-57. [PubMed: 22098317] 
18. Garcia-Caldero H, Rodriguez-Vilarrupla A, Gracia-Sancho J, et al. Tempol administration, a superoxide dismutase mimetic, reduces hepatic vascular resistance and portal pressure in cirrhotic rats. J Hepatol. 2011; 54:660-5. [PubMed: 21159403]

19. Yang YY, Lee KC, Huang YT, et al. Effects of N-acetylcysteine administration in hepatic microcirculation of rats with biliary cirrhosis. J Hepatol. 2008; 49:25-33. [PubMed: 18490076]

20. Gracia-Sancho J, Lavina B, Rodriguez-Vilarrupla A, et al. Enhanced vasoconstrictor prostanoid production by sinusoidal endothelial cells increases portal perfusion pressure in cirrhotic rat livers. J Hepatol. 2007; 47:220-7. [PubMed: 17459512]

21. Graupera M, March S, Engel P, et al. Sinusoidal endothelial COX-1-derived prostanoids modulate the hepatic vascular tone of cirrhotic rat livers. Am J Physiol Gastrointest Liver Physiol. 2005; 288:G763-70. [PubMed: 15550559]

22. Kawada N, Tran-Thi TA, Klein H, et al. The contraction of hepatic stellate (Ito) cells stimulated with vasoactive substances. Possible involvement of endothelin 1 and nitric oxide in the regulation of the sinusoidal tonus. Eur J Biochem. 1993; 213:815-23. [PubMed: 7682947]

23. Bauer M, Bauer I, Sonin NV, et al. Functional significance of endothelin B receptors in mediating sinusoidal and extrasinusoidal effects of endothelins in the intact rat liver. Hepatology. 2000; 31:937-47. [PubMed: 10733551]

24. Iwakiri Y. Endothelial dysfunction in the regulation of cirrhosis and portal hypertension. Liver Int. 2012; 32:199-213. [PubMed: 21745318]

25. Kawada N, Seki S, Kuroki T, et al. ROCK inhibitor Y-27632 attenuates stellate cell contraction and portal pressure increase induced by endothelin-1. Biochem Biophys Res Commun. 1999; 266:296-300. [PubMed: 10600496]

26. Pinzani M, Milani S, De Franco R, et al. Endothelin 1 is overexpressed in human cirrhotic liver and exerts multiple effects on activated hepatic stellate cells. Gastroenterology. 1996; 110:534-48. [PubMed: 8566602]

27. Rockey DC, Weisiger RA. Endothelin induced contractility of stellate cells from normal and cirrhotic rat liver: implications for regulation of portal pressure and resistance. Hepatology. 1996; 24:233-40. [PubMed: 8707268]

28. Medina J, Arroyo AG, Sanchez-Madrid F, et al. Angiogenesis in chronic inflammatory liver disease. Hepatology. 2004; 39:1185-95. [PubMed: 15122744]

29. Kim MY, Baik SK, Lee SS. Hemodynamic alterations in cirrhosis and portal hypertension. Korean J Hepatol. 2010; 16:347-52. [PubMed: 21415576]

30. Perri RE, Langer DA, Chatterjee $S$, et al. Defects in cGMP-PKG pathway contribute to impaired NO-dependent responses in hepatic stellate cells upon activation. Am J Physiol Gastrointest Liver Physiol. 2006; 290:G535-42. [PubMed: 16269521]

31. Rappaport AM, MacPhee PJ, Fisher MM, et al. The scarring of the liver acini (Cirrhosis). Tridimensional and microcirculatory considerations. Virchows Arch A Pathol Anat Histopathol. 1983; 402:107-37.

32. Taura K, De Minicis S, Seki E, et al. Hepatic stellate cells secrete angiopoietin 1 that induces angiogenesis in liver fibrosis. Gastroenterology. 2008; 135:1729-38. [PubMed: 18823985]

33. Thabut D, Routray C, Lomberk G, et al. Complementary vascular and matrix regulatory pathways underlie the beneficial mechanism of action of sorafenib in liver fibrosis. Hepatology. 2011; 54:573-85. [PubMed: 21567441]

34. Novo E, Cannito S, Zamara E, et al. Proangiogenic cytokines as hypoxia-dependent factors stimulating migration of human hepatic stellate cells. Am J Pathol. 2007; 170:1942-53. [PubMed: 17525262]

35. Nagy JA, Morgan ES, Herzberg KT, et al. Pathogenesis of ascites tumor growth: angiogenesis, vascular remodeling, and stroma formation in the peritoneal lining. Cancer Res. 1995; 55:376-85. [PubMed: 7529135]

36. Dill MT, Rothweiler S, Djonov V, et al. Disruption of Notch1 induces vascular remodeling, intussusceptive angiogenesis, and angiosarcomas in livers of mice. Gastroenterology. 2012; 142:967-977. e2. [PubMed: 22245843]

37. Sumanovski LT, Battegay E, Stumm M, et al. Increased angiogenesis in portal hypertensive rats: role of nitric oxide. Hepatology. 1999; 29:1044-9. [PubMed: 10094944] 
38. Sieber CC, Sumanovski LT, Stumm M, et al. In vivo angiogenesis in normal and portal hypertensive rats: role of basic fibroblast growth factor and nitric oxide. J Hepatol. 2001; 34:64450. [PubMed: 11434609]

39. Groszmann RJ, Kotelanski B, Cohn JN. Different patterns of porta-systemic shunting in cirrhosis of the liver studied by an indicator dilution technique. Acta Gastroenterol Latinoam. 1971; 3:1116. [PubMed: 4945484]

40. Bosch J, Pizcueta P, Feu F, et al. Pathophysiology of portal hypertension. Gastroenterol Clin North Am. 1992; 21:1-14. [PubMed: 1568769]

41. Abraldes JG, Iwakiri Y, Loureiro-Silva M, et al. Mild increases in portal pressure upregulate vascular endothelial growth factor and endothelial nitric oxide synthase in the intestinal microcirculatory bed, leading to a hyperdynamic state. Am J Physiol Gastrointest Liver Physiol. 2006; 290:G980-7. [PubMed: 16603731]

42. Huang HC, Haq O, Utsumi T, et al. Intestinal and plasma VEGF levels in cirrhosis: the role of portal pressure. J Cell Mol Med. 2012; 16:1125-33. [PubMed: 21801303]

43. Fernandez M, Vizzutti F, Garcia-Pagan JC, et al. Anti-VEGF receptor-2 monoclonal antibody prevents portal-systemic collateral vessel formation in portal hypertensive mice. Gastroenterology. 2004; 126:886-94. [PubMed: 14988842]

44. Geerts AM, De Vriese AS, Vanheule E, et al. Increased angiogenesis and permeability in the mesenteric microvasculature of rats with cirrhosis and portal hypertension: an in vivo study. Liver Int. 2006; 26:889-98. [PubMed: 16911473]

45. Van Steenkiste C, Geerts A, Vanheule E, et al. Role of placental growth factor in mesenteric neoangiogenesis in a mouse model of portal hypertension. Gastroenterology. 2009; 137:2112-24. e1-6. [PubMed: 19751735]

46. Fernandez M, Mejias M, Angermayr B, et al. Inhibition of VEGF receptor-2 decreases the development of hyperdynamic splanchnic circulation and portal-systemic collateral vessels in portal hypertensive rats. J Hepatol. 2005; 43:98-103. [PubMed: 15893841]

47. Fernandez M, Mejias M, Garcia-Pras E, et al. Reversal of portal hypertension and hyperdynamic splanchnic circulation by combined vascular endothelial growth factor and platelet-derived growth factor blockade in rats. Hepatology. 2007; 46:1208-17. [PubMed: 17654489]

48. Tiani C, Garcia-Pras E, Mejias M, et al. Apelin signaling modulates splanchnic angiogenesis and portosystemic collateral vessel formation in rats with portal hypertension. J Hepatol. 2009; 50:296-305. [PubMed: 19070926]

49. Mejias M, Garcia-Pras E, Tiani C, et al. Beneficial effects of sorafenib on splanchnic, intrahepatic, and portocollateral circulations in portal hypertensive and cirrhotic rats. Hepatology. 2009; 49:1245-56. [PubMed: 19137587]

50. Reiberger T, Angermayr B, Schwabl P, et al. Sorafenib attenuates the portal hypertensive syndrome in partial portal vein ligated rats. J Hepatol. 2009; 51:865-73. [PubMed: 19726100]

51. Huang HC, Wang SS, Hsin IF, et al. Cannabinoid receptor 2 agonist ameliorates mesenteric angiogenesis and portosystemic collaterals in cirrhotic rats. Hepatology. 2012; 56:248-58. [PubMed: 22290687]

52. Iwakiri, Y. The Systemic and Splanchnic Circulation. In: Gines, P.; Kamath, PS.; Arroyo, V., editors. Chronic Liver Failure, Mechanisms and Management. Humana Press; New York, NY: 2011.

53. Tsai MH, Iwakiri Y, Cadelina G, et al. Mesenteric vasoconstriction triggers nitric oxide overproduction in the superior mesenteric artery of portal hypertensive rats. Gastroenterology. 2003; 125:1452-61. [PubMed: 14598261]

54. Iwakiri Y, Tsai MH, McCabe TJ, et al. Phosphorylation of eNOS initiates excessive NO production in early phases of portal hypertension. Am J Physiol Heart Circ Physiol. 2002; 282:H2084-90. [PubMed: 12003815]

55. Moezi L, Gaskari SA, Liu H, et al. Anandamide mediates hyperdynamic circulation in cirrhotic rats via CB(1) and VR(1) receptors. Br J Pharmacol. 2006; 149:898-908. [PubMed: 17043671]

56. Batkai S, Jarai Z, Wagner JA, et al. Endocannabinoids acting at vascular CB1 receptors mediate the vasodilated state in advanced liver cirrhosis. Nat Med. 2001; 7:827-32. [PubMed: 11433348] 
57. Moleda L, Trebicka J, Dietrich P, et al. Amelioration of portal hypertension and the hyperdynamic circulatory syndrome in cirrhotic rats by neuropeptide $\mathrm{Y}$ via pronounced splanchnic vasoaction. Gut. 2011

58. Trebicka J, Leifeld L, Hennenberg M, et al. Hemodynamic effects of urotensin II and its specific receptor antagonist palosuran in cirrhotic rats. Hepatology. 2008; 47:1264-76. [PubMed: 18318439]

59. Kemp W, Krum H, Colman J, et al. Urotensin II: a novel vasoactive mediator linked to chronic liver disease and portal hypertension. Liver Int. 2007; 27:1232-9. [PubMed: 17919235]

60. Hennenberg M, Trebicka J, Kohistani AZ, et al. Vascular hyporesponsiveness to angiotensin II in rats with $\mathrm{CCl}(4)$-induced liver cirrhosis. Eur J Clin Invest. 2009; 39:906-13. [PubMed: 19522833]

61. Chu CJ, Wu SL, Lee FY, et al. Splanchnic hyposensitivity to glypressin in a haemorrhage/ transfused rat model of portal hypertension: role of nitric oxide and bradykinin. Clin Sci (Lond). 2000; 99:475-82. [PubMed: 11099389]

62. Chen CT, Chu CJ, Lee FY, et al. Splanchnic hyposensitivity to glypressin in a hemorrhagetransfused common bile duct-ligated rat model of portal hypertension: role of nitric oxide and bradykinin. Hepatogastroenterology. 2009; 56:1261-7. [PubMed: 19950773]

63. Heinemann A, Wachter CH, Fickert P, et al. Vasopressin reverses mesenteric hyperemia and vasoconstrictor hyporesponsiveness in anesthetized portal hypertensive rats. Hepatology. 1998; 28:646-54. [PubMed: 9731553]

64. Song D, Liu H, Sharkey KA, et al. Hyperdynamic circulation in portal-hypertensive rats is dependent on central c-fos gene expression. Hepatology. 2002; 35:159-66. [PubMed: 11786972]

65. Coll M, Martell M, Raurell I, et al. Atrophy of mesenteric sympathetic innervation may contribute to splanchnic vasodilation in rat portal hypertension. Liver Int. 2010; 30:593-602. [PubMed: 19968782]

66. Ezkurdia N, Coll M, Raurell I, et al. Blockage of the afferent sensitive pathway prevents sympathetic atrophy and hemodynamic alterations in rat portal hypertension. Liver Int. 2012; 32:1295-305. [PubMed: 22292477]

67. Fernandez-Varo G, Ros J, Morales-Ruiz M, et al. Nitric oxide synthase 3-dependent vascular remodeling and circulatory dysfunction in cirrhosis. Am J Pathol. 2003; 162:1985-93. [PubMed: 12759254]

68. Fernandez-Varo G, Morales-Ruiz M, Ros J, et al. Impaired extracellular matrix degradation in aortic vessels of cirrhotic rats. J Hepatol. 2007; 46:440-6. [PubMed: 17156884]

69. Seo YS, Shah VH. The role of gut-liver axis in the pathogenesis of liver cirrhosis and portal hypertension. Clin Mol Hepatol. 2012; 18:337-46. [PubMed: 23323248]

70. Frances R, Chiva M, Sanchez E, et al. Bacterial translocation is downregulated by anti-TNF-alpha monoclonal antibody administration in rats with cirrhosis and ascites. J Hepatol. 2007; 46:797803. [PubMed: 17321632]

71. Terai S, Ishikawa T, Omori K, et al. Improved liver function in patients with liver cirrhosis after autologous bone marrow cell infusion therapy. Stem Cells. 2006; 24:2292-8. [PubMed: 16778155]

72. Jang YO, Kim YJ, Baik SK, et al. Histological improvement following administration of autologous bone marrow-derived mesenchymal stem cells for alcoholic cirrhosis: a pilot study. Liver Int. 2013

73. Sakamoto M, Nakamura T, Torimura T, et al. Transplantation of endothelial progenitor cells ameliorates vascular dysfunction and portal hypertension in carbon tetrachloride-induced rat liver cirrhotic model. J Gastroenterol Hepatol. 2013; 28:168-78. [PubMed: 22849788]

74. Sakaida I, Terai S, Yamamoto N, et al. Transplantation of bone marrow cells reduces CCl4induced liver fibrosis in mice. Hepatology. 2004; 40:1304-11. [PubMed: 15565662]

75. Cardenas A, Bataller R, Arroyo V. Mechanisms of ascites formation. Clin Liver Dis. 2000; 4:44765. [PubMed: 11232200]

76. Barrowman JA, Granger DN. Effects of experimental cirrhosis on splanchnic microvascular fluid and solute exchange in the rat. Gastroenterology. 1984; 87:165-72. [PubMed: 6724260]

77. Chung C, Iwakiri Y. The lymphatic vascular system in liver diseases: its role in ascites formation. Clin Mol Hepatol. 2013; 19:99-104. [PubMed: 23837133] 
78. Ribera J, Pauta M, Melgar-Lesmes P, et al. Increased nitric oxide production in lymphatic endothelial cells causes impairment of lymphatic drainage in cirrhotic rats. Gut. 2013; 62:138-45. [PubMed: 22267600]

79. Takuma Y, Nouso K, Morimoto Y, et al. Measurement of spleen stiffness by acoustic radiation force impulse imaging identifies cirrhotic patients with esophageal varices. Gastroenterology. 2013; 144:92-101. e2. [PubMed: 23022955]

80. Colecchia A, Montrone L, Scaioli E, et al. Measurement of spleen stiffness to evaluate portal hypertension and the presence of esophageal varices in patients with HCV-related cirrhosis. Gastroenterology. 2012; 143:646-54. [PubMed: 22643348]

81. Berzigotti A, Seijo S, Arena U, et al. Elastography, spleen size, and platelet count identify portal hypertension in patients with compensated cirrhosis. Gastroenterology. 2013; 144:102-111. e1. [PubMed: 23058320]

82. Mori K, Arai H, Abe T, et al. Spleen stiffness correlates with the presence of ascites but not esophageal varices in chronic hepatitis C patients. Biomed Res Int. 2013; 2013:857862. [PubMed: 23984413]

83. Mejias M, Garcia-Pras E, Gallego J, et al. Relevance of the mTOR signaling pathway in the pathophysiology of splenomegaly in rats with chronic portal hypertension. J Hepatol. 2010; 52:529-39. [PubMed: 20206401]

84. Iwakiri Y, Grisham M, Shah V. Vascular biology and pathobiology of the liver: Report of a singletopic symposium. Hepatology. 2008; 47:1754-63. [PubMed: 18393322]

85. Tashiro K, Satoh A, Utsumi T, et al. Absence of Nogo-B (reticulon 4B) facilitates hepatic stellate cell apoptosis and diminishes hepatic fibrosis in mice. Am J Pathol. 2013; 182:786-95. [PubMed: 23313137]

86. Zhang D, Utsumi T, Huang HC, et al. Reticulon 4B (Nogo-B) is a novel regulator of hepatic fibrosis. Hepatology. 2011; 53:1306-15. [PubMed: 21480333] 


\section{Key Points}

- The primary cause of portal hypertension in liver cirrhosis is increased intrahepatic vascular resistance.

- A reduction of intrahepatic vascular resistance could ameliorate portal hypertension.

- Arterial vasodilation in the splanchnic and systemic circulations worsens portal hypertension. 


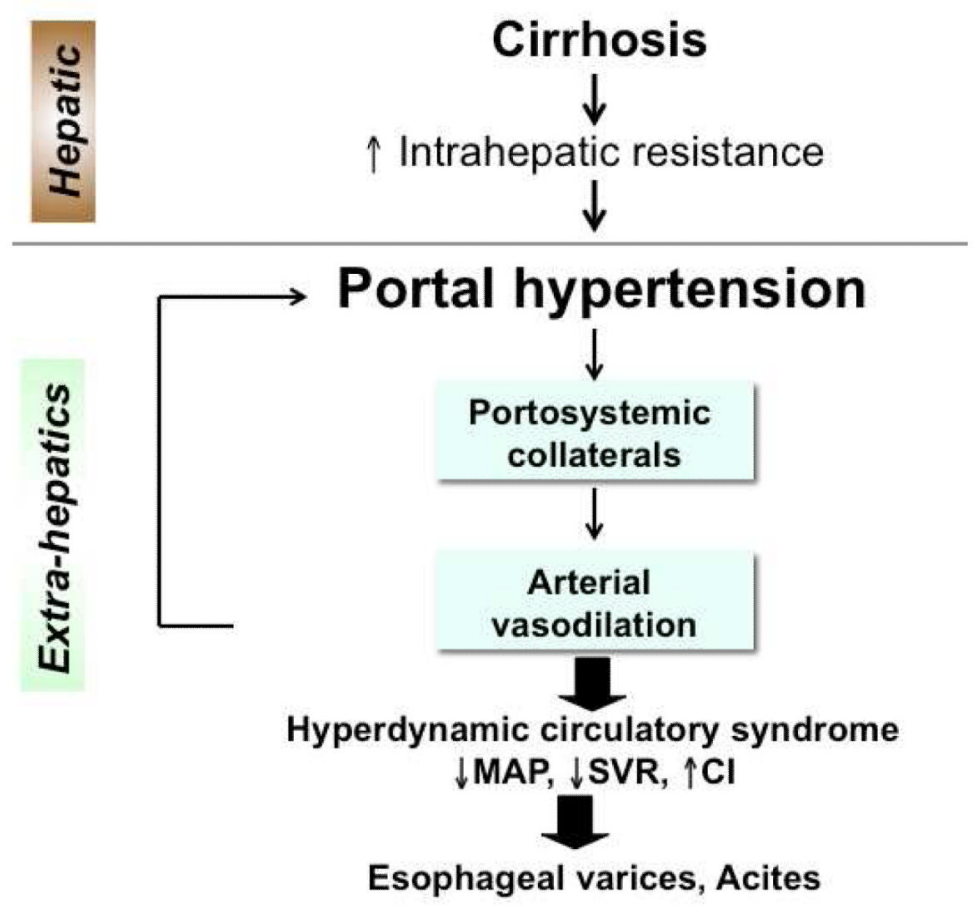

Figure 1.

Portal hypertension leads to the development of the hyperdynamic circulatory syndrome, characterized by decreased mean arterial pressure (MAP), decreased systemic vascular resistance (SVR) and increased cardiac index (CI). 


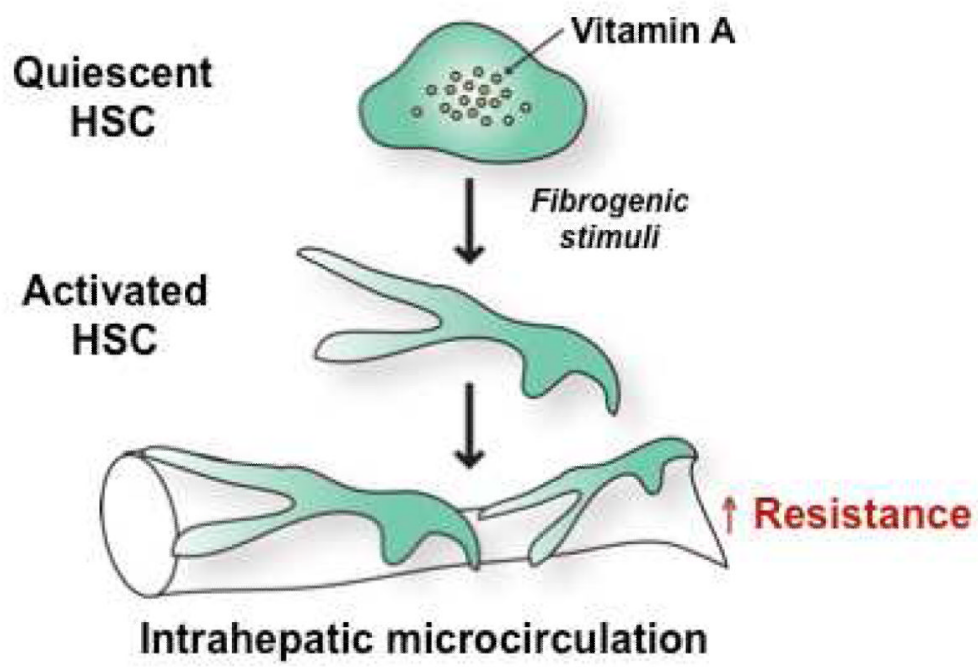

Figure 2. Activated hepatic stellate cells (HSCs) in liver cirrhosis increase intrahepatic vascular resistance

Quiescent HSCs are vitamin A storage cells and found in normal livers. In response to fibrogenic stimuli, such as transforming growth factor beta, HSCs are activated to become myofibroblasts, which exhibit a contractile and fibrogenic (collagen-producing) phenotype. These activated HSCs, located underneath liver sinusoidal endothelial cells, exert a contractile effect on the hepatic microcirculation, resulting in an increase in intrahepatic resistance. 